\title{
АДАПТАЦІЙНІ ОЗНАКИ КОРІВ ЗА ЗМІНИ УМОВ УТРИМАННЯ УПРОДОВЖ ЗИМОВОГО ТА ЛІТНЬОГО ПЕРІОДІВ РОКУ
}

\author{
Борщ Олександр Олександрович \\ кандидат сільськогосподарських наук, доцент \\ Білоцерківський національний аграрний університет \\ ORCID: 0000-0002-8450-2109 \\ E-mail: borshcha@outlook.com \\ Борщ Олександр Васильович \\ кандидат сільськогосподарських наук, доцент \\ Білоцерківський національний аграрний університет \\ ORCID: 0000-0001-5174-1309 \\ E-mail: aaborshch@ukr.net \\ Бабенко Олена Іванівна \\ кандидат сільськогосподарських наук, доцент \\ Білоцерківський національний аграрний університет \\ ORCID: 0000-0002-8404-3272 \\ E-mail: lelya.babenko1978@gmail.com
}

Метою чієї роботи було вивчити вплив сезону року на продуктивні і етологічні показники та комфорт корів (II i III лактацій) української чорно-рябої молочної породи при зміні умов утримання і доїння упродовж адаптаційного періоду. Дослідження проводили у СВК «Острійківське» (Білоцерківський район, Київська область) на коровах II $і$ III лактацій, котрих переводили із капітального приміщення у легкозбірне упродовж літнього ( $n=34)$ та зимового ( $n=58)$ періодів. Поголів'я корів утримувалось упродовж листопада-березня прив'язно у приміщенні капітального типу (ДхШхВ 76х12х6 м) на 100 голів, а упродовж квітня-жовтня - безприв'язно на вигульних майданчиках. Доїння відбувалось у приміщенні на установиі УДМ-200. Тварин було переведено до легкозбірного приміщення з безприв'язно-боксовим утриманням на 400 голів (100х36х10,5 м) з доїнням у доїльному залі на установиі «Карусель». Дослідження проводили упродовж адаптаційного періоду (30 діб після зміни умов утримання). Адаптаційний період було розділено на VI періодів тривалістю у 5 діб кожен. Доведено вплив сезону року на адаптаційні ознаки корів II і III лактацій до зміни умов утримання та доїння. Поведінкові реакиії у групі тварин, котрих переводили у нові умови утримання і доїння упродовж 30-денного адаптаційного періоду у теплі місяиі року (квітень-жовтень) відповідали рекомендованим показникам відповідно до графріку «ідеального дня» для молочних корів починаючи з IV періоду (16 доба), а у групі корів котрі змінювали умови утримання в холодний період (листопад-березень) - починаючи з VI періоду (26 доба). До того ж у групі тварин, котрі змінили умови утримання в теплий період року, спостерігали вищі значення чотирьох індексів комфорту для боксового утримання корів та продуктивності (на 2,04-2,60 кг >; P<0,95), порівняно з групою корів, котрих переводили у нові умови утримання і доїння упродовж холодHOго nepiody.

Ключові слова: молочні корови, адаптація, технології утримання і доїння, комфорт, продуктивність.

DOI: https://doi.org/10.32845/bsnau.lvst.2021.4.12

В умовах соціально-економічних трансформацій, що відбуваються нині в агропромисловому комплексі, забезпечення промисловості сільськогосподарською сировиною, а населення продуктами харчування є актуальним соціальним завданням сільськогосподарського виробництва та умовою продовольчої безпеки. Процеси збільшення виробництва тваринницької продукції та підвищення її якості тісно пов'язані з комфортними умовами утримання, котрі мають бути забезпечені для тварин [16]. Створення комфортних для молочних корів умов сприяє зменшенню захворюваності тварин, підвищенню їхньої продуктивності та збільшенню термінів продуктивного використання $[6,19]$.

Сучасне молочне скотарство засноване на спеціалізації, концентрації та кооперуванні виробництва, агропромисловій інтеграції, застосуванні комплексної механізації та автоматизації, що забезпечують високу продуктивність праці при рівномірному цілорічному виробництві продукції, ефективному використанні кормів та основних фондів підприємств. Крім того, важливим ффактором ефективності тваринництва $€$ удосконалення технологій утримання, підвищення

збереження та продуктивності корів, поліпшення якості продукції. Промислове виробництво молока базується на тісному зв'язку організаційно-технологічних, соціальноекономічних і біологічних систем. Сполучною ланкою, що забезпечує їх органічну єдність, є життєвий організм $[1,4,5]$. На сьогодні технології в молочному скотарстві передбачають використання спеціалізованих приміщень з механізмами та обладнанням, які мають забезпечувати комфортні умови для тварин та отримання високоякісної продукції за мінімального ступеня впливу на навколишнє середовище $[11,13]$.

Важливим моментом в одержанні великої кількості високоякісного молока $є$ забезпечення комфортного відпочинку для корів, який формується такими фракторами як оптимальна температура навколишнього середовища (у діапазоні від -5 до $\left.+25^{\circ} \mathrm{C}\right)$, сухе і м'яке лігво, оптимальні довжина і ширина стійла $[7,8]$. Через постійність обмінних процесів організм великої рогатої худоби дуже вразливий до дії температури навколишнього середовища. Особливо це відчувається у періоди тривалих низько- або високотемператур-

Вісник Сумського національного аграрного університету 
них навантажень, а також у періоди адаптації тварин до нових умов утримання. Порушення обмінних і терморегуляційних процесів прямо впливає на тривалість та характер поведінкових і фізіологічних реакцій та викликає стрес у тварин. Тривалий температурний стрес часто стає причиною коливання показників продуктивності, якісного складу молока та проблем із відтворенням і в сукупності негативно впливає на рентабельність виробництва продукції $[10,20]$.

Вагомим стрес-фактором у молочному скотарстві $€$ обмежений рух тварин. Активний рух тварин у будь-яку погоду за винятком гальмівних умов (дощ, сніг, сильний вітер) та одночасна інсоляція тварин $є$ невід'ємним фактором підтримання стану здоров'я та отримання максимальної молочної продуктивності.

Для фізіології тварини важливим є рух, який підтримує кровообіг, особливо у віддалених частинах тіла (кінцівках), що є профілактикою захворювань кінцівок і поліпшує обмін речовин. За прив'язного утримання корів часто виникають випадки порушення опорно-рухового апарату кінцівок. При цьому зміна умов утримання у повновікових корів при їх переведенні із прив'язного на безприв'язний спосіб часто характеризується не лише втратою продуктивності упродовж адаптаційного періоду, а й невідповідністю основних показників добової поведінки науково обгрунтованим нормам $[12,18]$.

Вибір варіанту утримання для тварин є важливим рішенням у молочному скотарстві та впливає на добробут тварин, продуктивність, якість молока та відтворні ознаки [3]. Зміна умов утримання для корів II і старше лактацій є стресфактором, котрий може впливати на поведінкові (упродовж періоду адаптації) та продуктивні ознаки (як упродовж періоду адаптації, так і за період господарського використання).
У своїх дослідженнях група науковців із Польщі та Бразилії вказують, що на тривалість адаптації до нового середовища існування (утримання) за поведінковими реакціями корів впливає сезон року [2]. У тварин, котрим змінювали умови утримання упродовж весняно-осіннього (термонейтрального) періоду, показники продуктивних, поведінкових, біоенергетичних та гематологічних ознак були більш оптимальними порівняно з аналогами, котрі адаптувались до нових умов утримання у зимовий період (низькотемпературний).

Нашою метою було вивчити вплив сезону року на продуктивні і етологічні показники та комфорт корів II і III лактацій української чорно-рябої молочної породи при зміні умов утримання і доїння упродовж адаптаційного періоду.

Матеріали та методи досліджень. Дослідження проводили у СВК «Острійківське» (Білоцерківський район, Київська область) на коровах II і III лактацій, котрих переводили із капітального приміщення у легкозбірне упродовж літнього ( $n=34)$ та зимового $(n=58)$ періодів. Поголів'я корів утримувалось упродовж листопада-березня на прив'язі у приміщенні капітального типу (ДхШхВ 76х12х6 м) на 100 голів, а упродовж квітня-жовтня - безприв'язно на вигульних майданчиках. Доїння відбувалось у приміщенні на установці УДМ-100. Тварин обох груп через 15-20 добу після отелення було переведено на іншу ферму з безприв'язно-боксовим утриманням на 400 голів (ДхШхВ: 100×36x10,5 м) з доїнням у доїльному залі на установці «Карусель». Середньомісячні значення температури повітря у приміщеннях визначали за даними метеостанції (Wifi) MISOL WS-WH2950 (Китай), а навколишнього середовища - за даними Українського гідрометеорологічного центру. Динаміку річної температури повітря у приміщеннях до та після зміни умов утримання корів наведено у таблиці 1 .

Таблиця 1

Динаміка річної температури повітря у приміщенні після і після зміни умов утримання корів

\begin{tabular}{|c|c|c|}
\hline \multirow[b]{3}{*}{ Місяці } & \multicolumn{2}{|c|}{ Середня температура повітря у приміщенні по місяцях, ${ }^{\circ} \mathrm{C}$} \\
\hline & \multicolumn{2}{|c|}{ Варіант утримання } \\
\hline & $\begin{array}{c}\text { До змін умов утримання: } \\
\text { - стійлово-прив'язне у капітальному приміщенні на } 100 \text { голів } \\
\text { (листопад-березень) на вигулах (квітень-жовтень) }\end{array}$ & $\begin{array}{c}\text { Після змін умов утримання: } \\
\text { - безприв'язно-боксове у легкозбірному приміщенні на } 400 \text { голів }\end{array}$ \\
\hline I & $8,3 \pm 0,34$ & $1,9 \pm 0,13^{* * *}$ \\
\hline II & $5,6 \pm 0,22$ & $0,8 \pm 0,07^{* \star *}$ \\
\hline III & $10,5 \pm 0,49$ & $4,9 \pm 0,31^{* \star *}$ \\
\hline IV & $11,8 \pm 0,52$ & $10,4 \pm 0,69$ \\
\hline $\mathrm{V}$ & $16,4 \pm 0,79$ & $17,7 \pm 0,98$ \\
\hline $\mathrm{VI}$ & $20,8 \pm 1,24$ & $21,1 \pm 1,40$ \\
\hline VII & $24,2 \pm 2,37$ & $22,9 \pm 2,56$ \\
\hline VIII & $24,3 \pm 2,48$ & $22,3 \pm 2,02$ \\
\hline IX & $14,9 \pm 0,68$ & $15,8 \pm 0,72$ \\
\hline $\mathrm{X}$ & $6,3 \pm 0,17$ & $7,7 \pm 0,47^{\star \star}$ \\
\hline $\mathrm{XI}$ & $9,7 \pm 0,48$ & $3,8 \pm 0,25^{* \star *}$ \\
\hline XII & $9,4 \pm 0,55$ & $2,4 \pm 0,19^{* * *}$ \\
\hline
\end{tabular}

Примітка: ${ }^{* *}-P \geq 0,99 ;{ }^{* * *}-P \geq 0,999$ порівняно з середньою температурою повітря до зміни умов

Дослідження проводили упродовж адаптаційного періоду (30 діб після зміни умов утримання). Адаптаційний період було розділено на VI періодів тривалістю у 5 діб кожен. Добову поведінку корів вивчали упродовж 2-х суміжних діб, при цьому через кожні 10 хвилин у піддослідних групах фіксували кількість корів, які на час спостереження споживали корм, відпочивали лежачи, стояли, рухались та пили воду. Також для визначення кількості підходів до кормового стола фіксували номер кожної окремої корови із числа тих, котрі споживають корм. Тривалість основних поведінкових реакцій прирівнювали до графіка «ідеального дня» згідно 3 яким не менше ніж 50\% тривалості доби тварини мають відпочивати у положенні лежачи, 20-21\% - споживати корми, до 10\% - ходити та 2-4\% пити воду [12]. Комфорт умов утримання тварин визначали за індексом комфорту корів (відношення корів котрі, лежать у боксах, до корів, які контактують з боксом); індексом стояння корів (відношення корів котрі стоять у боксах, до корів, які контактують з боксом); індексом дискомфорту (кількість корів, котрі стоять двома передніми кінцівками у стійлі, а задніми ногами у гнойовому 
каналі до корів, які контактують із стійлом) та індексом використання стійла (відношення корів, котрі лежать у боксах, до решти корів, крім тих, що споживають корм) $[9,14,15,17]$.

Матеріали досліджень обробляли методом варіаційної статистики на основі розрахунку середнього арифметичного, середньоквадратичної похибки та достовірності різниці між порівнюваними показниками. Вірогідність отриманих результатів і різницю між показниками розраховували за $t$ критерієм Стьюдента. Для показу вірогідності в таблицях прийнято умовні позначення $\mathrm{P}>0,95 ; \mathrm{P}>0,99 ; \mathrm{P}>0,999$, які у статті відповідно позначені зірочками $\left({ }^{* * * * ; * *}\right)$.

Результати досліджень. Динаміка основних показ- ників поведінки корів упродовж літньої адаптації за показниками відпочинку лежачи та напування переважала дані отримані упродовж зимової адаптації (табл. 2). Тривалість відпочинку лежачи улітку була на 17-34 хв довшою, порівняно з зимовими показниками ( $P>0,99$ і $P>0,95$ у I та II періодах відповідно), а напування - на 4-6 хв ( $P>0,999$ упродовж I-VI періодів). Відповідно узимку дещо довшими були показники тривалості ходьби (9-15 хв) та стояння (12-17 хв) корів. В цілому тривалість актів поведінки упродовж літньої адаптації відповідала рекомендованим значенням починаючи 3 IV (16 доба) періоду, а упродовж зимової - з VI періоду (26 доба).

Таблиця 2

Показники поведінки корів II і III лактацій упродовж літнього і зимнього адаптаційних періодів

\begin{tabular}{|c|c|c|c|c|c|c|}
\hline \multirow{2}{*}{$\begin{array}{c}\text { Тривалість } \\
\text { акту поведінки, хв }\end{array}$} & \multicolumn{5}{|c|}{ Періоди (доба) } \\
\cline { 2 - 7 } & $\begin{array}{c}\text { I } \\
(1-5)\end{array}$ & $\begin{array}{c}\text { III } \\
(6-10)\end{array}$ & $\begin{array}{c}\text { IV } \\
(11-15)\end{array}$ & $\begin{array}{c}\text { VI } \\
(16-20)\end{array}$ & $\begin{array}{c}\text { VI } \\
(21-25)\end{array}$ \\
\hline \multicolumn{7}{|c|}{ (26-30) }
\end{tabular}

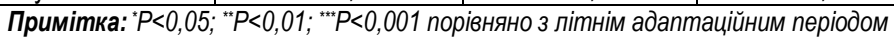

Значення індексу комфорту упродовж адаптаційного періоду улітку відповідала рекомендованим значенням починаючи з IV періоду, а узимку - з VI періоду (табл. 3). За показником індексу стояння упродовж зимового адаптаційного періоду рекомендовані значення спостерігали почина- ючи з 11-15 доби (III період). Показники індексів дискомфорту та використання стійл улітку відповідали рекомендованим нормам, починаючи з II та V періодів, а узимку - 3 III та VI періодів відповідно.

Значення індексів, котрі характеризують комфорт корів упродовж адаптаційного періоду

\begin{tabular}{|c|c|c|c|c|c|c|c|}
\hline \multirow[b]{2}{*}{ Індекси } & \multirow[b]{2}{*}{$\begin{array}{c}\text { Рекомендовані } \\
\text { значення }\end{array}$} & \multicolumn{6}{|c|}{ Періоди (доба) } \\
\hline & & $\begin{array}{c} \\
(1-5) \\
\end{array}$ & $\begin{array}{c}11 \\
(6-10) \\
\end{array}$ & $\begin{array}{c}\text { III } \\
(11-15) \\
\end{array}$ & $\begin{array}{c}\text { IV } \\
(16-20) \\
\end{array}$ & $\begin{array}{c}\mathrm{V} \\
(21-25) \\
\end{array}$ & $\begin{array}{c}\mathrm{VI} \\
(26-30) \\
\end{array}$ \\
\hline \multicolumn{8}{|c|}{ Літо $n=34$} \\
\hline Індекс комфорту, \% & 85 і більше & 70,24 & 73,82 & 78,33 & 86,64 & 88,26 & 90,54 \\
\hline Індекс стояння, \% & не більше 20 & 18,68 & 16,53 & 15,45 & 9,12 & 7,53 & 6,78 \\
\hline Індекс дискомфорту, \% & не більше 10 & 11,08 & 9,65 & 6,22 & 4,24 & 4,21 & 2,68 \\
\hline Індекс використання стійла, \% & 75 і більше & 54,19 & 59,07 & 66,38 & 71,66 & 78,43 & 82,26 \\
\hline \multicolumn{8}{|c|}{ 3има $n=58$} \\
\hline Індекс комфорту, \% & 85 і більше & 64,50 & 76,33 & 82,78 & 85,76 & 90,61 & 91,66 \\
\hline Індекс стояння, \% & не більше 20 & 23,34 & 20,66 & 19,28 & 14,48 & 12,09 & 6,27 \\
\hline Індекс дискомфорту, \% & не більше 10 & 12,16 & 11,03 & 7,16 & 6,19 & 5,16 & 2,07 \\
\hline Індекс використання стійла, \% & 75 і більше & 48,79 & 54,27 & 61,74 & 67,22 & 72,16 & 82,39 \\
\hline
\end{tabular}

Вітчизняні та іноземні науковці в галузі молочного скотарства повідомляють, що поряд із генотиповими факторами, котрі впливають на продуктивність корів, вагоме значення на цю ознаку має сезон (пора) року $[3,16]$. У своїх дослідженнях ми порівнювали вплив пори року (літо і зима) на продуктивність корів II і III лактацій після зміни умов ут- римання і доїння. Встановлено, що пора року впливає на продуктивність корів при зміні типу приміщення (капітальне на легкозбірне) (табл. 4). Продуктивність упродовж 30-ти денного адаптаційного періоду була вищою у літній період порівняно з зимовим (на 2,04-2,60 кг, $\mathrm{P}<0,95)$.

Добові надої корів II і III лактацій упродовж літнього і зимнього адаптаційних періодів, кг

\begin{tabular}{|c|c|c|c|c|c|c|}
\hline \multirow[b]{2}{*}{ Пора року } & \multicolumn{6}{|c|}{ Періоди (доба) } \\
\hline & $\begin{array}{c} \\
(1-5) \\
\end{array}$ & $\begin{array}{c}11 \\
(6-10) \\
\end{array}$ & $\begin{array}{c}\text { III } \\
(11-15)\end{array}$ & $\begin{array}{c}\text { IV } \\
(16-20)\end{array}$ & $\begin{array}{c}\mathrm{V} \\
(21-25)\end{array}$ & $\begin{array}{c}\mathrm{VI} \\
(26-30)\end{array}$ \\
\hline $\begin{array}{c}\text { Літо } \\
\mathrm{n}=34 \\
\end{array}$ & $\begin{array}{c}21,77 \pm \\
0,70 \\
\end{array}$ & $\begin{array}{c}22,08 \pm \\
0,73 \\
\end{array}$ & $\begin{array}{c}22,38 \pm \\
0,64 \\
\end{array}$ & $\begin{array}{c}23,03 \pm \\
0,78 \\
\end{array}$ & $\begin{array}{c}23,21 \pm \\
0,80 \\
\end{array}$ & $\begin{array}{c}23,34 \pm \\
0,81 \\
\end{array}$ \\
\hline $\begin{array}{l}\text { Зима } \\
n=58\end{array}$ & $\begin{array}{c}19,73 \pm \\
0,69^{*}\end{array}$ & $\begin{array}{c}19,89 \pm \\
0,71^{*}\end{array}$ & $\begin{array}{c}20,32 \pm \\
0,73^{*}\end{array}$ & $\begin{array}{c}20,55 \pm \\
0,73^{*}\end{array}$ & $\begin{array}{c}20,67 \pm \\
0,75^{*}\end{array}$ & $\begin{array}{c}20,74 \pm \\
0,75^{*}\end{array}$ \\
\hline
\end{tabular}

Вісник Сумського національного аграрного університету 
Примітка: * $P<0,95$ порівняно з літнім адаптаційним періодом

Висновки. Доведено значення впливу сезону року на адаптаційні ознаки корів II і III лактацій до зміни умов утримання та доїння. Поведінкові реакції групи тварин котрих переводили у нові умови утримання (з прив'язного у капітальних приміщеннях на безприв'язне у легко збірних) і доїння (з стійлового у молокопровід на доїльну установку «Карусель») упродовж 30-денного адаптаційного періоду у теплі місяці року (квітень-жовтень) були більш наближені до оптимальних (згідно з графріком «ідеального дня» для молочних корів); у них були вищі значення чотирьох індексів комфорту для боксового утримання та вища продуктивність (на 2,04-2,60 кг >; Р<0,95) порівняно з групою корів, котрих переводили у нові умови утримання і доїння упродовж зимового періоду.

\section{Список використаної літератури:}

1. Angrecka S. and Herbut P. Conditions for cold stress development in dairy cattle kept in free stall barn during severe frosts. Czech Journal of Animal Science. 2015. issue 60(2), pp. 81-87. doi: https://doi.org/10.17221/7978-CJAS

2. Angrecka S., Herbut P., Godyń D., Vieira F.M.C. and Zwolenik M. Dynamics of Microclimate Conditions in Freestall Barns During Winter - a Case Study from Poland. Journal of Ecological Engineering. 2020. issue 5, pp. 129-136. doi: https://doi.org/10.12911/22998993/122235

3. Bewley J.M., Robertson L.M. and Eckelkamp E.A. A 100-Year Review: Lactating dairy cattle housing management. Journal of Dairy Science. 2017. issue 100 (12), pp. 10418-10431. doi: https://doi.org/10.3168/jds.2017-13251

4. Borshch A.A., Ruban S., Borshch A.V. and Babenko O.I. Effect of three bedding materials on the microclimate conditions, cows behavior and milk yield. Polish Journal of Natural Science. 2019. issue 34 (1), pp. 19-31.

5. Borshch O.O., Gutyj B.V., Sobolev O.I., Borshch O.V., Ruban S.Yu., Bilkevich V.V., Dutka V.R., Chernenko O. M., Zhelavskyi M. M. and Nahirniak T. Adaptation strategy of different cow genotypes to the voluntary milking system. Ukrainian Journal of Ecology. 2020a. issue 10(1), pp. 145-150. doi: https://doi.org/10.15421/2020_23.

6. Borshch O.O., Ruban S.Yu., Gutyj B.V., Borshch O.V., Sobolev O.I., Kosior L.T., Fedorchenko M.M., Kirii A.A., Pivtorak Y.I., Salamakha I.Yu., Hordiichuk N.M., Hordiichuk L.M., Kamratska O.I. and Denkovich B.S. Comfort and cow behavior during periods of intense precipitation. Ukrainian Journal of Ecology. 2020b. issue 10(6), pp. 98-102. doi: https://doi.org/10.15421/2020_265

7. Borshch O.O., Borshch O.V., Sobolev O.I., Nadtochii V.M., Slusar M.V., Gutyj B.V., Polishchuk S.A., Malina V.V., Korol A.P., Korol-Bezpala L.P., Bezpalyi I.F., and Cherniavskyi O.O. Wind speed in easily assembled premises with different design constructions for side curtains in winter. Ukrainian Journal of Ecology. 2021a. issue 11(1), pp. 325-328. https://doi.org/10.15421/2021_49

8. Borshch O.O., Ruban S.Yu. and Borshch O.V. The influence of genotypic and phenotypic factors on the comfort and welfare rates of cows during the period of global climate changes. Agraarteadus. 2021b. issue 1, pp. 25-34. doi: https://doi.org/10.15159/jas.21.12

9. Cook N.B., Bennett, T.B. and Nordlund K.V. Monitoring indices of cow comfort in free-stall-housed dairy herds. Journal of Dairy Science. 2005. issue 88, pp. 3876-3885. doi: https://doi.org/10.3168/jds.S0022-0302(05)73073-3

10. Fabris T.F., Laporta J., Skibiel A.L., Corra F.N., Senn B.D., Wohlgemuth S.E., and Dahl G.E. Effect of heat stress during early, late, and entire dry period on dairy cattle. Journal of Dairy Science. 2019. issue 102, pp. 5647-5656. doi: https://doi.org/10.3168/jds.2018-15721

11. Hempel S., Menz C., Pinto S., Galan E., Janke D., Estellés F., Müschner-Siemens T., Wang X., Heinicke J., Zhang G., Amon B., del Prado A. and Amon T. Heat stress risk in European dairy cattle husbandry under different climate change scenarios uncertainties and potential impacts. Earth System Dynamics. 2019. issue 10, pp. 859-884. doi: https://doi.org/10.5194/esd-10-8592019

12. Krawczel P. and Grant R. Effect of cow comfort on milk quality, productivity and behavior. Pages 15-24 in Proc. 48th Annu. Meet. Natl. Mastit. Counc., Charlotte, NC. 2009. National Mastitis Council, Verona, WI.

13. Leiva T., Cooke R.F., Brandão A.P., Schubach K.M., Batista L.F.D., Miranda M.F., Colombo E.A., Rodrigues R.O., Junior J.R.G., Cerri R.L.A. and Vasconcelos, J.L.M. Supplementing an immunomodulatory feed ingredient to modulate thermoregulation, physiologic, and production responses in lactating dairy cows under heat stress conditions. Journal of Dairy Science. 2017. issue 100(6), pp. 4829-4838. doi: https://doi.org/10.3168/jds. 2016-12258.

14. Nelson A.J. On-farm nutrition diagnostics. Pages 76-85 in Proc. 29th Annu. Conf. Am. Bovine Pract., San. Diego, CA. 1996. Am. Assoc. Bovine Pract., Rome, GA.

15. Overton M.W., Sischo W.M., Temple G.H. and Moore D.A. Using time-lapse video photography to assess dairy cattle lying behavior in a free-stall barn. Journal of Dairy Science. 2002. issue 85, pp. 2407-2413. doi: https://doi.org/10.3168/jds.S00220302(02)74323-3.

16. Ruban S., Borshch O.O., Borshch O.V., Orischuk O., Balatskiy Y., Fedorchenko M., Kachan A., and Zlochevskiy M. The impact of high temperatures on respiration rate, breathing condition and productivity of dairy cows in different production systems. Animal Science Papers and Reports. 2020. issue 38(I), pp. 61-72.

17. Tucker C.B., Weary D.M. and Fraser D. Influence of neck-rail placement on free-stall preference, use, and cleanliness. Journal of Dairy Science. 2005. issue 88, pp. 2730-2737. doi: https://doi.org/10.3168/jds.S0022-0302(05)72952-0

18. Vaculikova M., I. Komzakova I. and Chladek G. The effect of low air temperature on behaviour and milk production in holstein dairy cows. Acta Universitatis Agricultural Silviculturae Mendelianae Brunensis. 2017. issue 65, pp. 1623-1627. doi: https://doi.org/10.11118/actaun201765051623

19. Vitt R., Weber L., Zollitsch W., Hörtenhuber S.J., Baumgartner J., Niebuhr K., Piringer M., Anders I., Andre K., Hennig- 
Pauka I., Schönhart M. and Schauberger G. Modelled performance of energy saving air treatment devices to mitigate heat stress for confined livestock buildings in Central Europe. Biosystems Engineering. 2017. issue 164, pp. 85-97. doi: https://doi.org/10.1016/j.biosystemseng.2017.09.013

20. von Keyserlingk M.A.G., Martin N.P., Kebreab E., Knowlton K.F., Grant R.J., Stephenson M., Sniffen C.J., Harner J.P., Wright A.D., and Smith S.I. Invited review: Sustainability of the US dairy industry. Journal of Dairy Science. 2013. Issue 96, pp. 5405-5425. doi: https://doi.org/10. 3168/jds.2012-6354

\section{References:}

1. Angrecka, S., \& Herbut, P. 2015. Conditions for cold stress development in dairy cattle kept in free stall barn during severe frosts. Czech Journal of Animal Science, 60(2), P. 81-87. doi: https://doi.org/10.17221/7978-CJAS

2. Angrecka, S., Herbut, P., Godyń, D., Vieira, F.M.C., \& Zwolenik, M. 2020. Dynamics of Microclimate Conditions in Freestall Barns During Winter - a Case Study from Poland. Journal of Ecological Engineering, 5, P. 129-136. doi: https://doi.org/10.12911/22998993/122235

3. Bewley, J.M., Robertson, L.M., \& Eckelkamp, E.A. 2017. A 100-Year Review: Lactating dairy cattle housing management. Journal of Dairy Science, 100 (12), P. 10418-10431. doi: https://doi.org/10.3168/jds.2017-13251

4. Borshch, A.A., Ruban, S., Borshch, A.V., \& Babenko, O.I. 2019. Effect of three bedding materials on the microclimate conditions, cows behavior and milk yield. Polish Journal of Natural Science, 34 (1), P. 19-31.

5. Borshch, O.O., Gutyj, B.V., Sobolev, O.I., Borshch, O.V., Ruban, S.Yu., Bilkevich, V.V., Dutka, V.R., Chernenko, O. M., Zhelavskyi, M. M., \& Nahirniak, T. 2020a . Adaptation strategy of different cow genotypes to the voluntary milking system. Ukrainian Journal of Ecology, 10(1), P. 145-150. doi: https://doi.org/10.15421/2020_23.

6. Borshch, O.O., Ruban S.Yu., Gutyj, B.V., Borshch, O.V., Sobolev, O.I., Kosior, L.T., Fedorchenko, M.M., Kirii, A.A., Pivtorak, Y.I., Salamakha, I.Yu., Hordiichuk, N.M., Hordiichuk, L.M., Kamratska, O.I., \& Denkovich, B.S. 2020b. Comfort and cow behavior during periods of intense precipitation. Ukrainian Journal of Ecology, 10(6), P. 98-102. doi: https://doi.org/10.15421/2020_265

7. Borshch, O.O., Borshch, O.V., Sobolev, O.I., Nadtochii, V.M., Slusar, M.V., Gutyj, B.V., Polishchuk, S.A., Malina, V.V., Korol, A.P., Korol-Bezpala, L.P., Bezpalyi, I.F., \& Cherniavskyi, 0.0. 2021a. Wind speed in easily assembled premises with different design constructions for side curtains in winter. Ukrainian Journal of Ecology. 11(1), P.325-328. https://doi.org/10.15421/2021_49

8. Borshch, O.O., Ruban, S.Yu., \& Borshch, O.V. 2021b. The influence of genotypic and phenotypic factors on the comfort and welfare rates of cows during the period of global climate changes. Agraarteadus, 1, P. 25-34. doi: https://doi.org/10.15159/jas.21.12

9. Cook, N.B., Bennett, T.B., \& Nordlund, K.V. 2005. Monitoring indices of cow comfort in free-stall-housed dairy herds. Journal of Dairy Science, 88, P. 3876-3885. doi: https://doi.org/10.3168/jds.S0022-0302(05)73073-3

10. Fabris, T.F., Laporta, J., Skibiel, A.L., Corra, F.N., Senn, B.D., Wohlgemuth, S.E., \& Dahl, G.E. 2019. Effect of heat stress during early, late, and entire dry period on dairy cattle. Journal of Dairy Science, 102, P. 5647-5656. doi: https://doi.org/10.3168/jds.2018-15721

11. Hempel, S., Menz, C., Pinto, S., Galan, E., Janke, D., Estellés, F., Müschner-Siemens, T., Wang, X., Heinicke, J., Zhang, G., Amon, B., del Prado, A., \& Amon, T. 2019. Heat stress risk in European dairy cattle husbandry under different climate change scenarios - uncertainties and potential impacts. Earth System Dynamics, 10, 859-884. doi: https://doi.org/10.5194/esd-10859-2019

12. Krawczel, P., \& Grant, R. 2009. Effect of cow comfort on milk quality, productivity and behavior. Pages 15-24 in Proc. 48th Annu. Meet. Natl. Mastit. Counc., Charlotte, NC. National Mastitis Council, Verona, WI.

13. Leiva, T., Cooke, R.F., Brandão, A.P., Schubach, K.M., Batista, L.F.D., Miranda, M.F., Colombo, E.A., Rodrigues, R.O., Junior, J.R.G., Cerri, R.L.A., \& Vasconcelos, J.L.M. 2017. Supplementing an immunomodulatory feed ingredient to modulate thermoregulation, physiologic, and production responses in lactating dairy cows under heat stress conditions. Journal of Dairy Science, 100(6), P. 4829-4838. doi: https://doi.org/10.3168/jds. 2016-12258.

14. Nelson, A.J. 1996. On-farm nutrition diagnostics. Pages 76-85 in Proc. 29th Annu. Conf. Am. Bovine Pract., San. Diego, CA. Am. Assoc. Bovine Pract., Rome, GA.

15. Overton, M.W., Sischo, W.M., Temple, G.H., \& Moore, D.A. 2002. Using time-lapse video photography to assess dairy cattle lying behavior in a free-stall barn. Journal of Dairy Science, 85, P. 2407-2413. doi: https://doi.org/10.3168/jds.S00220302(02)74323-3.

16. Ruban, S., Borshch, O.O., Borshch, O.V., Orischuk, O., Balatskiy, Y., Fedorchenko, M., Kachan, A., \& Zlochevskiy, M. 2020. The impact of high temperatures on respiration rate, breathing condition and productivity of dairy cows in different production systems. Animal Science Papers and Reports, 38(I), 61-72.

17. Tucker, C.B., Weary, D.M., \& Fraser, D. 2005. Influence of neck-rail placement on free-stall preference, use, and cleanliness. Journal of Dairy Science, 88, P. 2730-2737. doi: https://doi.org/10.3168/jds.S0022-0302(05)72952-0

18. Vaculikova, M., I. Komzakova, I., \& Chladek, G. 2017. The effect of low air temperature on behaviour and milk production in holstein dairy cows. Acta Universitatis Agricultural Silviculturae Mendelianae Brunensis, 65, P. 1623-1627. doi: https://doi.org/10.11118/actaun201765051623

19. Vitt, R., Weber, L., Zollitsch, W., Hörtenhuber, S.J., Baumgartner, J., Niebuhr, K., Piringer, M., Anders, I., Andre, K., Hennig-Pauka, I., Schönhart, M., \& Schauberger, G. 2017. Modelled performance of energy saving air treatment devices to mitigate heat stress for confined livestock buildings in Central Europe. Biosystems Engineering, 164, P. 85-97. doi: https://doi.org/10.1016/j.biosystemseng.2017.09.013 
20. von Keyserlingk, M.A.G., Martin, N.P., Kebreab, E., Knowlton, K.F., Grant, R.J., Stephenson, M., Sniffen, C.J., Harner, J.P., Wright, A.D., \& Smith, S.I. 2013. Invited review: Sustainability of the US dairy industry. Journal of Dairy Science. 96, P. 54055425. doi: https://doi.org/10. 3168/jds.2012-6354

Borshch Oleksandr Oleksandrovich, Candidate of Agricultural Sciences, Assistant professor

Borshch Oleksandr Vasiliovich, Candidate of Agricultural Sciences, Assistant professor

Babenko Olena Ivanivna, Candidate of Agricultural Sciences, Assistant professor

Bila Tserkva National Agrarian University (Bila Tserkva, Ukraine)

Adaptation signs of cows for changes of keeping conditions during the winter and summer periods

The aim of this work was to study the influence of the season on the productive and ethological indicators and comfort of cows (II and III lactations) of Ukrainian black-and-white dairy breed when changing conditions of milking and milking during the adaptation period. The research was carried out in Ostriykivske Agricultural Complex (Bila Tserkva district, Kyiv region) on cows of the second and third lactations which were transferred from the capital premises to the prefabricated one during the summer ( $n=34$ ) and winter $(n=58)$ periods. The number of cows was kept in a capital-type facility ( $L \times W \times H 76 \times 12 \times 6 \mathrm{~m})$ for 100 heads during November-March, and during April-October it was loose in the playgrounds. Milking took place indoors at the UDM-200 unit. The animals were transferred to an easily assembled room with a free-range and boxing content of 400 heads (150x36x10.5 m) with milking in the milking parlor at the Carousel installation. The studies were performed during the adaptation period (30 days after the change of detention conditions). The adaptation period was divided into VI periods lasting 5 days each. The influence of the season on the adaptive traits of cows of II and III lactations to the change of housing and milking conditions is proved. Behavioral reactions in a group of animals that were transferred to new housing and milking conditions during the 30-day adaptation period in the warm months of the year (April-October) corresponded to the recommended indicators according to the "ideal day" schedule for dairy cows starting from IV period (16 days), and in the group of cows that changed the conditions of keeping in the cold period (NovemberMarch) starting from the VI period (26 days). In addition, in the group of animals that changed the conditions of keeping in the warm period of the year, higher values of four indices of comfort for boxing cows and productivity (by 2.04-2.60 kg>; $P<0.95)$ were observed compared to the group of cows that were transferred in new conditions of keeping and milking during the cold period.

Key words: dairy cows, adaptation, technologies of keeping and milking, comfort, productivity.

Дата надходження до редакції: 21.09.2021 p. 